\title{
Francisco Xavier de Carrión y Ribas, un diplomático zamorano amigo de Jean-Jacques Rousseau
}

Diplomat Francisco Xavier de Carrión y Ribas, Jean-Jacques Rousseau's friend from Zamora

Fernando Calderón Quindós

Universidad de Valladolid

CES.XVIII, núm. 26 (2016), págs. 271-297 


\section{RESUMEN}

Rousseau cita varias veces en Las Confesiones el nombre del diplomático español Francisco Xavier de Carrión y Ribas, de quien muy poco se ha sabido hasta nuestras fechas. El artículo reconstruye su vida, desde su primer empleo conocido en el séquito de don Álvaro de Mendoza, sumiller de cortina de Felipe V, hasta su nombramiento como contador general de las Órdenes Militares. Entre sendos empleos, su actividad diplomática le llevó a recorrer media Europa como secretario de embajada siempre y como encargado de negocios alguna vez. Venecia, Estocolmo, Viena, París y Londres dibujan su singladura diplomática y trazan el itinerario de una vida marcada por las luchas de poder y aspiraciones territoriales de las naciones europeas. Hombre culto, Rousseau lo conoció en Venecia en el otoño de 1743, cuando el ginebrino contaba 31 años y el zamorano apenas 25 . Treinta años después, todavía se escribían.

\section{Palabras clave}

Francisco Xavier de Carrión, Jean-Jacques Rousseau, diplomacia, cortes europeas.

\section{AbSTRACT}

At times, Rousseau names the Spanish diplomat Francisco Xavier de Carrion y Ribas - who very little has been known to our dates- in his Confessions. The article rebuilds his life, from his first known job in the Don Alvaro de Mendoza's retinue, Phillipe V's «sumiller de cortina», until his appointment as chief accountant of the Military Orders. Between these two separate jobs, his diplomatic activity led him to travel over half Europe always as embassy secretary and seldom as «chargé d'affaires». Venice, Stockholm, Vienna, Paris and London draw his diplomatic parcours and trace the journey of a life marked by power struggles and the territorial aspirations of European nations. Educated men, Rousseau and Carrión met for the first time in Venice in 1743's autumn, when the former was 31 and Carrión just 25. Thirty years later, they still wrote each other.

KEY WORDS

Francisco Xavier de Carrión, Jean-Jacques Rousseau, diplomacy, European courts.

Recibido: 11 de marzo de 2016. Aceptado: 6 de septiembre de 2016. 


\section{Introducción}

En el elenco de nombres propios que desfilan por el relato de las Confesiones, Francisco Xavier de Carrión y Ribas ocupa un lugar discreto ${ }^{1}$. Con ocasión de uno de sus encuentros en París, el ginebrino ofrece de él una breve semblanza, y esa semblanza recoge, poco más o menos, lo que de Carrión se ha sabido hasta fechas muy recientes. En 1891, Cesáreo Fernández Duro, antiguo capitán de navío de la Armada Española e ilustre erudito zamorano, anota el nombre de nuestro diplomático en un inventario de hijos notables de la provincia de Zamora. La reseña es breve, y se limita a reproducir el contenido de una necrológica publicada en la Gaceta de Madrid de $1779^{2}$. Evidentemente, la Gaceta no menciona la relación del diplomático zamorano con el autor del Contrato Social, lo que tampoco hace Fernández Duro. Sí lo hace Ralfh Alexander Leigh, editor de la correspondencia completa de Rousseau, a quien debemos la publicación de las cartas conservadas entre el ilustrado suizo y el diplomático español ${ }^{3}$. En una de sus notas explicativas, Leigh anota además algunos detalles no conocidos de la vida de Carrión, detalles a los que se sumaron treinta años después los aportados por el prestigioso hispanista francés Didier Ozanam, antiguo director de la Casa de Velázquez. Su obra de 1998, Les diplomates espagnols du XVIII siècle, incluye un repertorio biográfico en el que Carrión, secretario de embajada en varias cortes europeas, está pre-

1 Mi especial agradecimiento a Blanca Tena Arregui, técnico de archivos del Archivo General de Simancas, y a Juan Carlos de la Mata Guerra, responsable del Archivo Municipal de Benavente. Sin su colaboración, este artículo no se habría escrito.

2 Cesáreo Fernández Duro, Colección Bibliográfico-Biográfica de Noticias referentes a la provincia de Zamora o Materiales para su Historia, Madrid, Manuel Tello, 1891. Fernández Duro remite a la Gaceta de Madrid del 26 de febrero, pág. 144: «El día 15 del corriente falleció en esta corte a la edad de 60 años el Sr. D. Francisco Xavier de Carrión, Regidor y Alcalde Mayor perpetuo de la ciudad de Zamora, Caballero de la Orden de Santiago, del Consejo de S.M., su Secretario y Contador general de las Ordenes Militares; en cuyo empleo y los anteriores que obtuvo de Secretario de Embajada en las cortes de París, Viena, Londres, Venecia y Suecia, habiendo estado en algunas de ellas encargado interinamente de los negocios, sirvió á S.M. por espacio de 39 años con notorio celo, desinterés y amor». En este y en el resto de documentos de la época, he actualizado la ortografía.

3 Correspondance complète de Jean-Jacques Rousseau, Ralph Alexander LeIGH ed, Ginebra, Institut et Musée Voltaire, 1965-1971 / Oxford, Voltaire Foundation, 1971-1989, LII vols. 
sente ${ }^{4}$. No informa Ozanam de su relación con Rousseau, pero establece y fija con exactitud su singladura diplomática, expuesta siempre a los vaivenes de la política internacional.

\section{Datos de familia, formación y primer empleo}

Francisco Xavier de Carrión y Ribas nació en Alcañices, localidad vecina de Portugal, el 6 de abril de $1718^{5}$. Pertenecía a una familia de la baja nobleza castellana. Entre los antepasados que recorren su árbol genealógico, se cuentan algunos miembros distinguidos. Por línea paterna destaca el nombre de Nicolás de Carrión, hermano del tatarabuelo de Francisco Xavier. El lustre y notoriedad de la familia nacen sin duda con él. La práctica de la venalidad, empleada asiduamente durante el reinado de Felipe IV para servir de socorro a los ejércitos, le permitió comprar el oficio de alcalde mayor de la ciudad de Zamora en 1636, y recibir la merced de un juro de quinientos ducados al año tras las Cortes celebradas en Madrid en $1647^{6}$. Regidor de Zamora y procurador de cortes por la misma ciudad, Nicolás de Carrión es además el fundador del mayorazgo de los Carriones ${ }^{7}$, institución del Antiguo Régimen que venía a perpetuar en la familia los títulos y derechos adquiridos por sus titulares sucesivos. Nicolás de Carrión murió sin descendencia, lo que hizo que el mayorazgo recayera en su sobrino Alonso de Carrión, bisabuelo de Francisco Xavier ${ }^{8}$, quien más tarde lo heredaría por derecho de primogenitura.

Alcañices fue la cuna de Carrión, y al marquesado de Alcañices estuvo vinculado, al menos, uno de los antepasados de Francisco Xavier, su abuelo Diego de Carrión. El marqués lo tuvo entre sus criados de mayordomo, y es posible que la cercanía con el linaje de los Enríquez tuviera alguna consecuencia en la futura formación de nuestro secretario. La familia Carrión debía disfrutar de una situación desahogada, y parecida debía ser la situación de la familia Ribas con la que aquella entroncaría como consecuencia del matrimonio de Juan Manuel de Carrión con Josefa de Ribas, padres de Francisco Xavier. La línea materna, en efecto, disponía también de hombres de calidad, y Alonso, abuelo materno

\footnotetext{
4 Didier Ozanam, Les diplomates espagnoles du XvIIIe siècle, Madrid - Bordeaux / Casa de Velázquez Maison des Pays Ibériques, 1998, págs. 215-216.

5 Archivo Histórico Diocesano de Zamora, AP. 26/4 f. 80v.

6 Archivo Municipal de Benavente [AMB], Fondo Casa de Doña Soledad González, leg. 2 (2), exp. 3.

7 AMB, Fondo Casa de Doña Soledad González, leg. 2 (2), exp. 5.

8 Así lo dispone Nicolás de Carrión en una escritura de donación irrevocable fechada el 26 de enero de 1647. AMB, Fondo Casa de Doña Soledad González, leg. 2 (2), exp. 5.
} 
del futuro secretario de embajada, se había ocupado de la tesorería general del conde duque de Benavente ${ }^{9}$, grande de España y padre de Josefa Pimentel, quien luego sería mecenas de Goya y anfitriona de uno de los principales salones literarios del Madrid finisecular.

Francisco Xavier mostró desde muy tempranas fechas aptitudes para el estudio. Un elogio fúnebre de 1780 lo describe como un «joven dotado de buena índole y de mucho talento». Se colige de ese mismo elogio que debió de cursar estudios de primeras letras y latinidad en Zamora y estudios superiores en Madrid, donde muy pronto habría manifestado «una decidida propensión al estudio de la política» ${ }^{10}$. En la corte había residido su abuela paterna, Catalina de Porras. Bien situada, era estimada de los señores marqueses de Villagarcía y de la condesa de Villardompardo, en cuya casa había pasado a servir como dama de honor su hija Antonia ${ }^{11}$. Es muy probable que la amistad de Catalina con la condesa fuera determinante en el primer empleo de su nieto. La condesa, en efecto, era hermana de don Álvaro de Mendoza, a la sazón Patriarca de las Indias Orientales, y de quien Francisco Xavier fue paje durante algunos meses, quizás durante algunos años ${ }^{12}$. D. Álvaro era además sumiller de cortina de Felipe V, lo que pudo a la postre favorecer la carrera diplomática de su joven empleado.

\section{Venecia}

En agosto de 1740, Felipe V designaba al conde de Bena-Maserano ministro plenipotenciario en la corte de San Petersburgo, y un jovencísimo Carrión (apenas contaba veintidós años), debía seguirle como secretario. La partida del conde se demoró diez meses ${ }^{13}$. Había pasado demasiado tiempo desde la emi-

$9 \quad$ AMB, Fondo Casa de Doña Soledad González, leg. 2, exp. 16.

10 Nos referimos al elogio leído en la Real Sociedad Económica Matritense de Amigos del País, de la que Carrión fue socio, por el secretario de la misma, don Miguel Sarralde, el 3 de junio de 1780. El elogio aparece recogido en el cuarto volumen de las Memorias de la Sociedad Económica, Imprenta de Don Antonio de Sancha, 1786, págs. 337-339.

11 Así lo aseguran algunos de los interrogados en Madrid con motivo de la petición formulada por Francisco Xavier para su admisión en la Orden de Santiago en la primavera de 1757. Por ejemplo, un tal Alonso de Rivera asegura haber conocido a Catalina en casa del Señor marqués de Villagarcía «con el motivo de ser dama principal de la señora condesa de Villardompardo doña Antonia de Carrión y Porrás, su hija». En Archivo Histórico Nacional [AHN], Órdenes, Santiago, exp. 1643, f. $104 v$.

12 Didier Ozanam, Les diplomates espagnols, pág. 215.

13 Sobre este percance y otros relacionados con la misión diplomática del conde de Bena-Maserano, véase el texto de Vicente Palacio Atard, «Una ignorada misión diplomática a Rusia en 1740», en Homenaje académico a D. Emilio García López, Madrid, Real Academia de la Historia (1993), págs. 267-280. 
sión de la Real Orden, y esa circunstancia vino a motivar un cambio imprevisto. Carrión debía preparar su equipaje para abandonar la corte por el extranjero, pero el destino ya no sería la fría y remota Moscovia, sino la bella y decadente Venecia. Allí debía ocuparse de la secretaría de la embajada de España y recibir órdenes de su titular, el marqués de Mari, patricio genovés de larga e impecable trayectoria al servicio de la corona de España. Si, como parece razonable, Carrión emprendió el viaje en compañía del marqués, debió de abandonar Madrid en los últimos días de marzo de 1741 para llegar a Venecia, previo paso por Génova, el 21 de junio ${ }^{14}$. En Venecia, alquiló el embajador genovés el imponente palazzo Grimani, a sólo un paso del puente de Rialto, por lo que es presumible que Carrión despachara la correspondencia de la embajada asomado al Gran Canal, y que fuera en ese palazzo renacentista donde tuviera lugar el primer encuentro entre Carrión y Rousseau.

Rousseau ocupó la secretaría de la embajada francesa en Venecia en septiembre de 1743, dos años y medio después del establecimiento de Carrión. Una carta de Rousseau dirigida a la condesa de Montaigu, esposa del embajador, nos cuenta el origen de la relación: «[El embajador de Francia] se ha mostrado siempre muy unido al embajador de España, y yo, por imitarle en su gusto tanto como mi estado lo permite, he formado con el secretario una amistad tan íntima que nos hemos hecho inseparables, de manera que nada se ve en Venecia tan unido como las dos casas de Francia y de España» ${ }^{15}$. Hacía apenas un mes de la firma en Fontainebleau del Segundo Pacto de Familia, y la alianza entre las dos coronas favorecía sin duda aquel clima de buen entendimiento.

Por aquel entonces, Rousseau era sólo un joven prometedor dotado de una especial sensibilidad para la música. Poco tiempo antes de abandonar suelo francés se había dado a conocer ante la Academia de las Ciencias de París con un proyecto de notación musical, y de las prensas había salido, en enero de 1743, una obra titulada Disertación sobre la música moderna. Venecia debía parte de sus encantos a la música, y Rousseau debió de tardar muy poco en consagrar sus ocios a esta distracción. Si hemos de hacerle caso, Carrión le acompañaba allí donde la música ofrecía ocasión de solazarse, y juntos acudían los domingos a los Mendicanti, casa de caridad y conservatorio al mismo tiempo, donde niñas huérfanas y de familias pobres recibían una esmerada formación musical. Ahora bien, Rousseau no sólo se dejaba seducir por aquellas voces angelicales. También componía música, y había traído de París los primeros

14 Del arribo del marqués de Mari a Venecia informa Luis de Buy en carta escrita al marqués de Villarías el 21 de junio de 1741. En Archivo General de Simancas [AGS], Estado, Venecia, leg. 5728.

15 Correspondance complète de Jean-Jacques Rousseau, I, pág. 212 (traducción nuestra. Esta advertencia es válida para todos los textos procedentes de la correspondencia de Rousseau recogidos en el artículo). 
compases de su ópera Las musas galantes. Rousseau los ensayaba con ayuda de una pequeña orquesta en casa de otro español, un tal Fagoaga ${ }^{16}$. Una bailarina llamada Bettina (quizás la misma Bettina de Casanova) bailaba los bailetes, y en aquellas hermosas veladas Carrión debió de integrar el selecto grupo de amigos del ginebrino.

A juzgar por el relato de las Confesiones, la amistad entre Carrión y Rousseau se inició en fechas tempranas al establecimiento en Venecia de este último. La alianza entre las dos coronas y, sobre todo, el frecuente trato entre sus embajadores respectivos, vino a propiciar el primer encuentro de los secretarios, aunque otros motivos habrían de propiciar los siguientes. La música, ya lo hemos visto, favoreció el entendimiento desde muy pronto. También, sin duda, el deseo compartido de practicar la galantería con las muchachas del lugar. Venecia no sorprende a Rousseau por su arquitectura, ante la que se muestra tan indiferente como Montaigne lo fue de la obra de Miguel Ángel o Corregio a su paso por Florencia. Sí le apasionan el carnaval, los múltiples festejos promovidos por una aristocracia ociosa, y las mujeres. Rousseau confiesa no haber frecuentado prostitutas ni mancebías. Prefería la oportunidad tomada al vuelo, y once meses de estancia en Venecia dieron lugar a más de un lance amoroso. Las Confesiones, por ejemplo, informan de que nuestros secretarios se encapricharon ambos de la señorita de Cataneo, una de las tres hijas del agente de Prusia en Venecia. Rousseau la deseaba, pero era Carrión quien la tenía. Incluso señala Rousseau que «se trató de casamiento». Los sueldos de Carrión y Rousseau no favorecían el despilfarro, pero el de este era sensiblemente inferior al de aquel, y esa circunstancia hizo que Rousseau emprendiera la retirada en una ciudad donde

16 Hasta la fecha, nadie ha arrojado luz acerca de la identidad de este tal Fagoaga. Sin embargo, es posible que se trate de José Joaquín Fagoaga, hijo del guipuzcoano establecido en México Francisco de Fagoaga e Yragorri (1679-1736). Francisco había pasado a América como teniente de navío en 1697, y su instinto empresarial pronto le convirtió en propietario de una fortuna inmensa. Casado en Ciudad de México con Josefa de Arozqueta, tuvo diez hijos. De la familia se conserva un retrato al óleo a los pies de la Virgen de Aranzazú, y de José Joaquín un hermoso retrato triunfal. Su padre lo envió a España para seguir la carrera de las armas. El 8 de febrero de 1743 participó como cadete en la batalla librada en Camposanto, localidad próxima a Módena, y en 1746 en las batallas de Piacenza (16 de junio) y de Río Tidone (9 de agosto), en ambas como coronel de infantería. El cargo le fue concedido por Felipe V después de que aquel se comprometiese a ofrecer servicio a la corona con la leva de cuatrocientos reclutas. Rousseau llegó a Venecia en septiembre de 1743, siete meses después de la batalla de Camposanto. Es posible que José Joaquín tuviera ocasión de solazarse en la Serenísima ese mismo año entre su bautismo en la carrera de las armas y su regreso a Madrid en 1745, donde habría emprendido las gestiones para obtener el rango de coronel de infantería. Sobre la Familia Fagoaga, puede consultarse el artículo de Xavier SANChIZ, «La familia Fagoaga. Apuntes genealógicos», en Estudios de Historia Novohispana, México, UNAM, Instituto de Investigaciones Históricas, nº 23 (2000), págs. 129-167. El retrato familiar de la familia Fagoaga y Arozqueta y el de José Joaquín han aparecido publicados a color en la revista-libro Artes de México, bajo el título «El retrato novohispano» (julio-agosto 1994) nº 25, págs. 3 y 4. 
«con un bolsillo tan escuálido no debe uno meterse a galanteador» ${ }^{17}$. A pesar de ello, a pesar de sus escasos ingresos, ambos se las arreglaron para entregarse a las más variadas distracciones, lo que hicieron sin causar desdoro en su reputación de hombres al servicio de la corona. Si hemos de hacer caso del testimonio de Rousseau, el embajador de Montaigu, a cuyo servicio estaba, recibía felicitaciones de «los embajadores y ministros del rey con quienes estábamos en correspondencia» ${ }^{18}$, y, por su parte, Carrión era respaldado efusivamente por su superior. En una de sus cartas, este reconoce el «celo y prudente conducta» ${ }^{19}$ de Carrión, y pide para él se le conceda el sueldo que desea obtener.

Los dos amigos compartían aficiones y empleo, y los dos parecían fijar sus ojos en las mismas mujeres. La joven de Cataneo había llamado la atención de ambos. No fue la única. Antes o después de que Carrión pensara en desposarla, los dos se pusieron de acuerdo en compartir los favores de una misma mujer, una niña de once o doce años llamada Anzoletta a la que su madre deseaba vender. Carrión la encontró, propuso el arreglo a Rousseau, y este aceptó. Sus propósitos eran deshonrosos. Sin embargo, ninguno de los dos abusó de la inocencia de Anzoletta. Como la muchacha tenía buena voz, le compraron una espineta y pagaron para ella las lecciones de un profesor de canto. Quedaron prendados de las gracias de la niña, pero «con un cariño paternal —anota Rousseau- en que tan poca parte tenían los sentidos» ${ }^{20}$.

Rousseau abandonó Venecia a finales de agosto de 1744. En octubre de ese año ocupa un apartamento en la parisina Rue Saint-Honoré. En el apartamento se alojaba otro español, Manuel Ignacio de Altuna y Portu, a quien Rousseau había conocido en Venecia, y a quien le unía una íntima amistad. De su correspondencia sólo se conserva una carta fechada el 30 de junio de 1748. La historia de su relación ha sido estudiada por la hispanista Cécile Mary Trojani, quien se hace eco de una tradición familiar según la cual «una señora piadosa destruyó, por escrúpulos de conciencia [...] las cartas que el autor del Contrato Social escribió a su amigo D. Manuel Ignacio» ${ }^{21}$. No es improbable que un destino parecido corriera la correspondencia de Rousseau con Carrión, de la que apenas se conserva un puñado de cartas. Las obras del ginebrino figuraban en el

17 Les Confessions, en Euvres complètes, Bernard Gagnebin y Marcel Raymond eds., París, Gallimard, La Pléiade, 1959, vol. I, pág. 316.

18 Les Confessions, pág. 305.

19 Venecia, 8 de agosto de 1744. De Mari a Villarías. AGS, Estado, Venecia, leg. 5735.

20 Les Confessions, pág. 323.

21 Citado en Cécile Mari Trojani, L'Écriture de l'Amitié dans l'Espagne des Lumières, Toulouse, Presses universitaires du Mirail, 2004, pág. 35, quien lo toma del artículo de Julio de Urquijo, «Los Amigos del País (según cartas y otros documentos inéditos del siglo XVIII)», Revista Internacional de Estudios Vascos, n. ${ }^{\circ} 17$ (1926), págs. 565-605. 
índice de los libros prohibidos, y la familia del zamorano pudo albergar el temor de recibir el escarmiento de las autoridades.

\section{Viena. Secretario de Grimaldi en misión «reservada y secreta»}

Carrión se mantuvo en Venecia hasta el otoño de 1745. Para entonces, hacía más de dos años que su padre había muerto, lo que comprometía el bienestar de sus tres hermanos Juan, Manuel y José Pablo. Suspiraba Francisco Xavier por volver a España, pero su protector, el marqués de Mari, prefería mantenerlo a su lado. Obediente, Carrión pasó con él a Lombardía para sumarse a la expedición del infante D. Felipe, futuro duque de Parma. El marqués de Mari había sido designado sumiller de corps de su Alteza Real, y esa circunstancia obligó a Carrión a permanecer en el ejército durante cuatro meses, hasta marzo de $1746^{22}$. En marzo está en Pavía; en abril, otra vez en Venecia, aunque sólo fugazmente. El marqués de Grimaldi debe cumplir las órdenes de una «misión reservada y secreta» en Viena, y Carrión recibe la orden de servirle como secretario. La Guerra de Sucesión Austriaca había dado lugar a reivindicaciones territoriales enfrentadas entre las potencias europeas, e Italia se convertía en uno de los principales escenarios de la contienda. La corona española deseaba recuperar el Milanesado, perdido a manos de Austria desde 1706. Creía contar para ello con la aquiescencia de la vecina Francia, pero esta había firmado con Cerdeña un ajuste que comprometía las aspiraciones españolas. La situación exigía una reacción inmediata por parte de la corte de Madrid, que decidió encomendar al marqués de Grimaldi una delicada misión cuyo objetivo consistía en concertar una paz separada con la Austria de la emperatriz María Teresa ${ }^{23}$.

Pese a actuar con todas las cautelas, Grimaldi teme ser descubierto por las autoridades de la capital imperial y abandona Viena por la más segura Linz en diciembre de 1746, cuando España aun sigue de luto por el fallecimiento de su rey Felipe V, e intenta acostumbrarse a la política de su hijo Fernando. Después, fugaz paso por Ferrara y Génova en el verano de 1747, y establecimiento en Parma, cuyo ducado volvería pronto a manos españolas tras la firma del Tratado de Aquisgrán el 18 de octubre de 1748. Allí permanecen Grimaldi y su secretario hasta el verano del año siguiente. En agosto, los dos dejan atrás el ducado

22 Conocemos estos datos por una carta dirigida por Carrión a Ricardo Wall con fecha de 28 de junio de 1754 (AGS, Estado, Alemania, leg. 6483).

23 Sobre este asunto y cualquier otro relacionado con Grimaldi, véase el trabajo de Paulino García DiEgo Jerónimo Grimaldi o el espectador afable: actividad diplomática y política: 1739-1784. Tesis Doctoral. UNED, Facultad de Geografía e Historia, Departamento de Historia Moderna, 2012. 
y se encaminan hacia Suecia, próximo destino en su singladura diplomática. Grimaldi ha recibido la orden de ocupar la embajada española en Estocolmo, y Carrión ha de ocuparse de la secretaría. El viaje les lleva por Munich, Dresde y Praga. El 17 de septiembre de 1747, tras más de cuarenta días, embajador y secretario llegan a Estocolmo.

\section{Estocolmo}

Los asuntos que ocupan los despachos de Grimaldi son de notable importancia a lo largo de sus cuatro años al frente de la embajada. Carrión le asiste en todo lo necesario. Su vocación de servicio y eficaz desenvoltura en los asuntos de la secretaria reciben el reconocimiento de su superior. Grimaldi está convencido de que ha aprovechado muy bien de los años que ha estado empleado», y destaca en particular su «conocimiento de cuatro lenguas además de la española» ${ }^{24}$. Como el marqués de Mari anteriormente, Grimaldi elogia la actitud de su subordinado. Conviene indicar, no obstante, que las palabras de encomio no surgen espontáneamente. En uno y otro caso, Carrión se ha quejado primero de unos honorarios que apenas le alcanzan para vivir decentemente, y sendos embajadores deciden interceder en su favor. Grimaldi lo hará en diversas ocasiones, una de ellas a fin de que Carrión reciba la merced del hábito de Santiago, de la que el secretario se considera merecedor «en atención a sus méritos, y al imponderable esmero con que corresponde a la piedad de V.M.» ${ }^{25}$. El 8 de octubre de 1751 Grimaldi puede comunicar a Carrión que su petición ha sido favorablemente atendida.

Grimaldi es solicitado en Hannover por las autoridades españolas en el mes de junio de 1752. Carrión tiene entonces 34 años y, en ausencia de su superior, él es ahora el hombre fuerte de la legación. La primera carta como encargado de negocios la firma el 16 de junio. Una semana antes ha escrito a Carvajal, secretario de Estado, en términos que reflejan su turbación por el nombramiento: «Venero como debo Exmo. Sr. las órdenes de vd. y recibo esta con extremo gozo y con inexplicable zozobra: contrarios efectos que produce una causa misma» ${ }^{26}$. La dieta, apunto de concluir, interesa en la corte de Madrid, y Carrión informa de todos los pormenores hasta su desenlace. Incluso traduce el discurso pronunciado por el Primer Ministro, el conde de Tessin, a los Estados del Reino.

\footnotetext{
24 Estocolmo, 28 de noviembre de 1749. De Grimaldi a Carvajal. AGS, Estado, Suecia, leg. 6678.

25 Estocolmo, 11 de junio de 1751. De Carrión a Carvajal. AGS, Estado, Suecia, leg. 6679.

26 Estocolmo, 9 de junio de 1752. De Carrión a Carvajal. AGS, Estado, Suecia, leg. 6680.
} 
Desea hacerse valer ante Carvajal. Está contento de su reputación y se jacta en especial de su amistad con el presidente de la Cancillería Johan von Höpken. Carrión anota con complacencia los amables gestos con que el canciller le honra en sus semanales conferencias con los ministros extranjeros: es una prueba indirecta de su valía. Sus despachos, sin embargo, apenas recogen noticias de interés en los primeros meses: los reyes se alojan en su palacio veraniego de Drottningholm sin la menor novedad, Estocolmo es un desierto, y, en cuanto a él, no conoce el arte de gacetero ${ }^{27}$. Sin nada reseñable que anotar en la correspondencia con la secretaría de Estado, las cartas comentan largamente asuntos sin importancia, como las celebraciones de Navidad de 1753, los festejos por el cumpleaños del príncipe real, o la caza del lobo, todo con tal de complacer a Carvajal, a quien informa también del curioso modo en que la reina consorte Luisa Ulrica, esposa de Adolfo Federico, cura su dolor de muelas:

El remedio - anota- consiste en coger un caracol y romper y quebrar su concha sin achucharle. Para evitar lo que pueda tener de asqueroso su contacto se pone entre dos lienzos muy finos como de muselina, y se aplica vivo sobre el carrillo del lado en que se padece la fluxión o dolor, y se tiene hasta que muerto y corrompiéndose el animal empieza a oler mal. Si el incomodo no cesa con el primero se repite en la misma forma la aplicación de otro, y se pretende que rara vez se necesita pasar al tercero ${ }^{28}$.

Carrión desea a Carvajal que no tenga que emplear tales remedios, e informa de sus continuos e insufribles dolores de muelas antes de conocer este específico.

Los despachos de Carrión no son todos igualmente anodinos. Dos visitas de paisanos ilustres, ambos de paso por Estocolmo, van a dar color a su correspondencia: Bernardo Ward y Antonio de Ulloa. La política reformista del marqués de la Ensenada había encontrado con la firma de la Paz de Aquisgrán de 1748 un escenario felizmente favorable, y por fin podía emprenderse una campaña de rápida modernización del país. A tal fin, era prioritario movilizar el capital intelectual y contratar los servicios de los hombres más capaces para visitar las distintas cortes europeas y tomar nota de cuanto pudiera resultar de provecho para mejorar el estado del reino. Bernardo Ward, economista de origen irlandés, más tarde ministro, llega a Estocolmo con ese objetivo pocos días después de la partida de Grimaldi hacia Hannover. Carrión le presenta al barón

${ }_{27}$ Estocolmo, 11 de agosto de 1752. De Carrión a Carvajal. AGS, Estado, leg. 6680.

28 Estocolmo, 16 de febrero de 1753. De Carrión a Carvajal. AGS, Estado, Estocolmo, leg. 6681. 
de Höpken, y ambos acuden al sitio de Drottingholm «para hacer la corte a la reina y príncipes ${ }^{29}$. Tras apenas un mes en Estocolmo, Ward embarca en un navío ruso camino de San Petersburgo. Ha sido la suya —anota Carrión- una «corta mansión en este país», aunque «bastante para que su mérito haya sido conocido, y le hayan hecho todos las correspondientes atenciones» ${ }^{30}$. Un año antes, a finales del mes de septiembre de 1751, Ulloa había llegado a Estocolmo procedente de la vecina Copenhague. Le acompañaban dos guardiamarinas y un alférez de infantería, su hermano Fernando. Grimaldi los recibe e informa de su llegada el 1 de octubre. En su singladura por otras cortes europeas, la visita de Ulloa había pasado casi desapercibida. Las labores de espionaje industrial que el marqués de la Ensenada le había encomendado exigían actuar con la mayor cautela, pero Suecia lo recibió con vítores y clamoreo. Grimaldi lo presenta ante sus majestades suecas e informa a Carvajal de la impresión causada por el científico español:

Los talentos, luces, ciencia, y conocimiento general de D. Antonio de Ulloa en casi todas las materias, le ganan la más distinguida estimación de todos y de las gentes de letras y académicos de aquí y de Uppsala; pero especialmente de esta reina, que, como quien puede, por su aplicación a las ciencias y bellas letras, dar su voto en ellas, desea, admira, y está muy pagada de su conversación, y me ha dicho que sentía no se detuviese aquí este caballero todo el invierno para entretenerse con él más tiempo ${ }^{31}$.

Grimaldi no parece exagerar. La estancia De Ulloa, como la de Ward, apenas se había prolongado por espacio de un mes, el de octubre de 1752, pero esa visita fugaz seguía recordándose en palacio transcurrido casi un año cuando, ausente ya Grimaldi, Carrión entrega al rey la traducción francesa de la obra que ha dado a su paisano fama universal: Rélation historique du voyage fait à l'Amérique meridional. El rey acepta el regalo y, en prueba de agradecimiento, le concede el honor de hacerle entrar en su gabinete. El nombre de Ulloa aparece una vez más en la correspondencia de Carrión. Antes de abandonar Estocolmo, el científico sevillano ha ordenado la fabricación de varios instrumentos científicos al maestro Daniel Ekström, mano derecha de Celsius, para su empleo en la Academia. El importe queda anotado en la cuenta de gastos extraordinarios firmada por Carrión el 9 de octubre de 1753, y de la traducción del recibo

\footnotetext{
29 Estocolmo, 7 de julio de 1752. De Carrión a Carvajal. AGS, Estado, leg. 6680.

30 Estocolmo, 28 de julio de 1752. De Carrión a Carvajal. AGS, Estado, leg. 6680.

31 Estocolmo, 1 de octubre de 1751. De Grimaldi a Ensenada, AGS, Marina, leg. 712, f. 733.
} 
extendido por Ekström se desprende que Ulloa ha ordenado la fabricación de «un instrumento geográfico de latón con dos tubos, y los demás requisitos; un micrómetro con un tubo astronómico de 81/2 pies de largo, y su máquina de iluminación; $[y]$ tres cajas de encina con chapas de latón y dos de pino para los dichos instrumentos» ${ }^{32}$. Convenientemente embalados, los instrumentos viajan en una fragata sueca de vela para Alicante.

La ciencia, la botánica en particular, ocupa varios despachos de Carrión. El secretario de Estado le ha pedido emprender las gestiones necesarias para hacerse con simiente de dos plantas nativas del país sueco e información sobre los cuidados para su mejor conservación. Carrión no pierde el tiempo y escribe al gran maestro de la botánica sueca, el profesor Carl Linné ${ }^{33}$, quien a su vez le dirige a un agricultor de la provincia de Escania, aficionado a la historia natural, para la obtención de las semillas. Una vez recibidas, Carrión las desprende del papel maltratado en que van envueltas y, con buen criterio, las pone dentro de una caja a fin de que resistan «al traqueo de los carros y al garroteo de las valijas cuando de uno u otro modo caminen según los países» ${ }^{34}$. En cuanto a la información sobre su cultivo, Carrión traduce por indicación de Linné varios pasajes de su Skånska resa (1751), aquellos en que se describen las dos especies: el carrizo (Arundo arenaria L.) y la hierba lyme (Elymus arenarius L. $)^{35}$. El secretario español se muestra tan cuidadoso y prolijo como en todo lo demás. Ganarse la confianza de Carvajal es fundamental si desea ver engrosados sus honorarios, aunque en este asunto también parece haber algo de interés personal, de gusto por los estudios científicos. El 21 de septiembre de 1753, en efecto, Carrión anota en su correspondencia que ha asistido la víspera a la asamblea de la Academia de las Ciencias «en el lugar que llaman Observatorio». «Extranjero y solo — añade—, se me permitió el acceso». Los reyes de Suecia están presentes, y es el presidente de la cancillería el encargado de dar lectura a «un discurso muy elegante y bien compuesto» ${ }^{36}$. Carrión no da más detalles ni comenta el contenido del discurso. Es sabido, no obstante,

32 AGS, SSH, leg. 5, f. 348.

33 No era la primera ocasión en que Linné entraba en contacto con la embajada española. Poco tiempo antes, Grimaldi había solicitado los servicios de su discípulo Pehr Löfling para que este pasara a España y diera a conocer las teorías de su maestro. Sobre la penetración de la botánica linneana en territorio peninsular, consúltese el artículo de Antonio González Bueno, «La difusión de las ideas linneanas en la España de la Ilustración», Actes d'Història de la Ciència i de la Tècnica (Nova Época), vol. I, no 2 (2008), págs. 183-203.

34 Estocolmo, 10 de agosto de 1753. De Carrión a Carvajal. AGS, Estado, Suecia, leg. 6681.

35 La correspondencia de Carrión con Linné se ha perdido. No así la del profesor sueco con José de Carvajal. Dos de ellas fueron publicadas por Camille Pitollet en «Deux lettres inédites de Ch. Linné relatives à l'Espagne», Revue des langues romanes, n 54 (1911), págs. 74-88. Debo esta indicación, así como el nombre científico de las especies requeridas por el secretario de Estado, al profesor Antonio González Bueno.

36 Estocolmo, 21 de septiembre de 1753. De Carrión a Carvajal. AGS, Estado, Suecia, leg., 6681. 
que Höpken se congratulaba en él del estado de prosperidad de las ciencias en territorio sueco, y que vinculaba el reciente lustre de la actividad científica nacional con el dilatado período de gobierno de los «sombreros» ${ }^{37}$. Höpken no olvidaba la contribución de Linné, recientemente nombrado caballero de la Orden de la Estrella Polar. Con él, la botánica había dejado atrás su larga existencia como caprichoso arte de la memoria, para convertirse en ciencia y dotarse de fundamentos propios ${ }^{38}$.

Las penurias económicas de Carrión, silenciadas durante meses, vuelven a ocupar un lugar en su correspondencia. La situación es insostenible. Nuestro hombre se desespera:

Llega el término ahora — escribe- que el corazón se apoca y desmaya por la fatal consecuencia del desdoro que se me sigue de mantenerme aquí sin el estipendio necesario [...] Yo no sé pedir a vd. lo que no merezco. Le pido y ruego por cuanto pueda mover su ánimo generoso el que alcance de la piedad del rey nuestro señor la asignación necesaria para mantenerme en la misma decencia que hasta aquí. Sin ella, confieso a vd. será extremo mi sonrojo y desazón, y que quisiera mejor pasarla entre los propios que a la vista de los extraños ${ }^{39}$.

Desde su arribo a Estocolmo, Carrión percibe un «corto sueldo» de doce mil reales de vellón. El dinero llega a veces con retraso, y el secretario carece de liquidez para saldar deudas con los prestamistas. Seriamente empeñado, logra mantener un «tren competente de tres criados, coche y decente menaje», y hacer su vida en una «casa vistosa y propia para hacerme considerar de los iguales» ${ }^{40}$. Tener menos equivaldría a dejar España en mal lugar. Las súplicas son insistentes. Carvajal responde con indignación. Entre tanto, cambios importantes se avecinan. La estancia de Carrión en Estocolmo toca a su fin. El marqués de Puentefuerte ha sido designado nuevo embajador de España en Suecia, y José Belezar se ocupará de la secretaría. Por su parte, Carrión ha

37 Llamados así en oposición a los «gorros (de dormir)», nombre con el que los partidarios del gobierno se referían a sus detractores, a los que acusaban de falta de patriotismo y de connivencia con las políticas territoriales rusas. Sobre la actividad diplomática española en suelo sueco en el siglo XVIII, el artículo de Paulino García Diego, «Un testimonio español sobre los asuntos de Suecia en la Era de la Libertad», en Tiempos Modernos, vol. VIII, nº 29 (2014), págs. 1-17. Sobre el discurso de Höpken, véase el trabajo de Sven Wismaly, profesor de la Universidad de Uppsala, «Science in Transit: Enlightenment Research Policy and Astronomy in Sweden», en The Journal of Astronomical Data, n 19 (2013), págs. 21-32.

38 Parafraseo un pasaje del discurso, citado en la obra de Dietrich Heinrich SToever, The Life of Sir Charles Linnaeus, Knight of the Swedish Order of the Polar Star, Londres, B. y J. White, 1794, pág. 209.

39 Estocolmo, 9 de octubre de 1753. De Carrión a Carvajal. AGS, Estado, Suecia, leg. 6681.

40 Estocolmo, 21 de septiembre de 1753. De Carrión a Carvajal. AGS, Estado, Suecia, leg. 6681. 
recibido el aviso de un nuevo destino. Seis años han pasado desde su establecimiento en Estocolmo.

\section{Viena}

Por orden de su majestad, Carrión debe ahora pasar a Viena, de nuevo como encargado de negocios. Es el mes de noviembre de 1754. El puerto sueco de Ystad, Berlín, Dresde y Praga jalonan el itinerario hasta su destino. Quiere que sus caballos vuelen, pero los caminos están impracticables. Son veintitrés días en que todo se opone a su solicitud. La clavija maestra del coche, incapaz de sortear con éxito las dificultades del camino, se rompe en dos ocasiones; los tornillos del cofre tampoco resisten la prueba, circunstancia que obliga a Carrión a pasar tres días en Berlín. Y cuando no son las averías, entonces son «las aguas, las nieves y los hielos» ${ }^{41}$. Después de soportar mil adversidades, Carrión todavía debe superar una más antes de franquear las puertas de la ciudad imperial. Los empleados de la aduana detienen el coche, lo registran de arriba abajo, meten mano a sus papeles y libros, requisan la libra de tabaco que había llevado a sus pies, y le obligan a pagar «cuatro úngaros». Carrión podría haber burlado la inspección si Antonio de Azlor, ministro plenipotenciario en Viena, hubiera enviado a las puertas de la ciudad coche y criado, servicio que Carrión había solicitado antes de abandonar Estocolmo, pero, por alguna razón, nadie estaba allí para salir en su auxilio ${ }^{42}$. El percance tuvo lugar el día de Noche Buena de 1754 y ocupa sus primeros despachos, en los que también hay lugar para hablar de diversas formalidades, e informar de otros asuntos igualmente menores. Su situación económica (otra vez su situación económica), le aflige. Representar los intereses de España exige ofrecer una imagen decorosa, y esa imagen no se mantiene sin gastos, sobre todo en una corte amante del juego y las diversiones ${ }^{43}$. Carrión se desespera porque el sueldo no le alcanza. Sin vestuario de verano, se apaña con su ropa vieja, más apropiada para los días de invierno. De lo que no puede prescindir es de un traje de gala si quiere representar a España en los festejos que, con motivo del aniversario de la emperatriz María Teresa, el 13 de mayo, prepara la corte. Y como necesita techo donde vivir, coche forrado de paño que lo lleve, caballos y criados que lo asistan..., Carrión se provee de todo al precio más ajustado. La relación de gastos de 6

\footnotetext{
41 Viena, 28 de diciembre de 1754. De Carrión a Wall. AGS, Estado, Alemania, leg. 6483.

42 Viena, 1 de febrero de 1755. De Carrión a Wall. AGS, Estado, Alemania, leg. 6483.

43 Viena, 5 de abril de 1755. De Carrión a Wall. AGS, Estado, Alemania, leg. 6483.
} 
de febrero introduce también otros conceptos de menor cuantía: tres libras de chocolate, dos de café con el azúcar, tres cuerdas de leña floja y una más de leña fuerte, cuatro libras de velas de cera, etc. Para entonces, hacía cerca de un mes que Antonio de Azlor, nuevo gobernador de Cádiz, había iniciado su regreso a España. Carrión debía encargarse él solo del real servicio, aunque sólo por un breve período de seis meses. El conde de Torrepalma, poeta y académico, ha sido nombrado ministro plenipotenciario en Viena y, tras dilatado paso por París, llega a la ciudad imperial el 9 de agosto de $1755^{44}$. Carrión sale a recibirle a las afueras de la ciudad en compañía de algunos nobles españoles, entre ellos el IV marqués de Almodóvar del Río. Su misión ha terminado. Al poco tiempo, el zamorano es informado de que el rey Fernando VI ha decidido concederle un sueldo de veinticuatro mil reales de vellón. Tras quince años de servicios ininterrumpidos fuera de España, por fin puede felicitarse de recibir una asignación que considera bien merecida. Después, la correspondencia semanal de Carrión se suspende. Torrepalma se ocupa de ella.

El 2 de noviembre de 1755 nace en Viena la archiduquesa María Antonia Josefa. Futura esposa de Luis XVI, María Antonieta tiene por padrinos a los reyes de Portugal, país que un día antes ha sido azotado por un terremoto de consecuencias devastadoras. Como la noticia tarda en llegar, los festejos por el nacimiento de la archiduquesa se celebran sin pesadumbre. Al poco tiempo, el 13 de diciembre, Carrión vuelve a escribir a Ricardo Wall (nuevo secretario de Estado desde abril del año anterior) a quien solicita permiso para volver a España. Debe ocuparse de la administración de sus bienes, y hacer efectiva por fin la merced del hábito de Santiago ${ }^{45}$. En reconocimiento a los servicios prestados, el Rey le concede una licencia de seis meses: por fin podrá ocuparse de sus asuntos. Carrión, sin embargo, abandona Viena mucho después, el 10 de junio. Ese mismo día, escribe a Ricardo Wall en los términos siguientes:

Sr., en el acto de ponerme en camino para esa corte dejo escrita esta carta para que el sábado parta con las de este Sr. ministro que también dará este aviso a vd. por si tuviere que mandarme en París. Espero que vd. no desapruebe el que me detenga allí algunos días para ver aquella corte que es el objeto de la curiosidad de todos, y que naturalmente excita la mía habiendo visto ya otras muchas de Europa $^{46}$.

44 Sobre la actividad del conde de Torrepalma al frente de la legación española en la capital imperial, véase la contribución del profesor Nicolás MARín LÓPEZ, «El conde de Torrepalma, ministro plenipotenciario en Viena (1755-1760)», en Cuadernos de Historia del Derecho, IV (1958), págs. 155-173.

45 Viena, 13 de diciembre de 1755. De Carrión a Wall. AGS, Estado, Alemania, leg. 6485.

46 Viena, 10 de junio de 1756. De Carrión a Wall. AGS, Estado, Alemania, leg. 6486. 
No era necesario dar más explicaciones. París era el centro del mundo y ofrecía reclamos innumerables. Entre ellos, tal vez, estrechar la mano de su amigo Rousseau, cuyo Discurso sobre la desigualdad hacía entonces mucho ruido.

\section{Zamora y Madrid}

Carrión llega a París probablemente a mediados del mes de junio. Para entonces, hacía cerca de dos meses que su amigo había abandonado la capital para instalarse en la casa de l'Ermitage, propiedad de Madame d'Épinay, en el cercano bosque de Montmorency. No sabemos si se vieron. Tampoco sabemos en qué fecha llegó a España, aunque hay un dato que permite situarlo en Zamora a principios de 1757. El 28 de enero, los caballeros hijosdalgo de Zamora se reúnen en Junta General para hacer solemne la admisión de Carrión en su gremio. Acompañado por dos comisarios, el secretario entra, da las gracias y toma asiento ${ }^{47}$. En abril, Carrión está en la corte, donde reside parte de su familia. Desde allí emprende diligencias para tomar posesión del mayorazgo de los Carriones, vacante desde la defunción de su padre catorce años antes ${ }^{48}$. Las diligencias obran el efecto deseado: el mayorazgo es suyo, y también lo es, en consecuencia, el título de Regidor y Alcalde Mayor Perpetuo de la ciudad de Zamora. Esa misma primavera, Carrión efectúa sus pruebas de ingreso en la Orden de Santiago. Para cumplir con la petición formulada por nuestro secretario, el Consejo designa dos informantes. Cuarenta y seis días de diligencias y un sinfín de interrogatorios por tierras de Benavente, Alcañices, Zamora, Toledo y Madrid permiten confirmar que Carrión es cristiano antiguo y que supera con éxito las pruebas exigidas de legitimidad, limpieza y nobleza. La concesión tiene lugar el 25 de junio. Sus días en España se acaban. Una Real Orden de 6 de noviembre de ese mismo año envía a Carrión de nuevo a París, donde debe asumir labores de secretario al servicio del embajador español Jaime Masones de Lima, conde de Montalvo. Para cumplir con su nueva comisión en Francia, el Rey le concede un sueldo de quinientos doblones de oro al año, y otros quinientos como ayuda de costa para su viaje y establecimiento ${ }^{49}$. Los seis meses de licencia concedidos por Su Majestad habían expirado un año antes, pero, por razones que ignoramos, Carrión ha

47 AHN, Órdenes, Santiago, exp. 1643, pág. $93 v$.

48 AMB, leg. 2, exp. 24.

49 AGS, DGT, Inv. 16, g. 22, leg. 51 (año de 1757). 
logrado prolongar su estancia en España otros doce meses, hasta noviembre de 1757.

\section{París}

El reencuentro con la capital de Francia ocurre el 19 de diciembre de 1757, después de algo más de un mes circulando por «malos caminos». Es un invierno gélido. El embajador informa de que el frío «es excesivo» en París, y de que «falta muy poco para que la Sena se hiele enteramente» ${ }^{50}$. De salud delicada, Jaime Masones prefiere mantenerse al calor de la estufa, y es Carrión quien varias veces hace la corte al Rey Luis XV y demás personas reales. Son días de luto: el infante D. Antonio de Portugal, la reina de Polonia María Josefa de Austria, y la Princesa Carolina de Inglaterra han fallecido recientemente. El negro se impone en el vestuario de la corte, y la legación española se ve obligada a encargar la confección de los trajes.

Un día, con su manto caballeroso, con su encomienda de la orden de Santiago al cuello, el zamorano se aleja de París para visitar a su amigo Jean-Jacques. Si Venecia los encontró juntos por última vez, ya son catorce los años sin verse. Determinar con exactitud el día del reencuentro no es posible, pero es muy probable que tuviera lugar a comienzos de octubre de 1758, ya que el día 8 de ese mismo mes Rousseau da indicaciones a su compatriota Coindet para que reparta varios ejemplares de su Carta a d'Alembert, recién salida de las prensas, de los que dos debe recibirlos Carrión, quien se aloja en el hotel du Molé, sito en la calle Saint Dominique, una de las arterias principales del distinguido faubourg Saint Germain ${ }^{51}$. De lo que no hay duda es de que fue en Montmorency donde los dos amigos se vieron aquella jornada. El 15 de diciembre de 1757, Rousseau había concluido el traslado de sus muebles de la casa de l'Ermitage al «petit Mont-Louis», y fijado aquí su nueva residencia. El propietario del inmueble se lo había cedido a cambio de un modesto alquiler, y en ese lugar solitario pasaría Rousseau los siguientes cinco años, los más prolíficos de su carrera de autor. Poco tiempo antes de concluida la mudanza, el ginebrino había roto con el «círculo de los literatos». Perdidas esas amistades, todavía le quedaba en París un puñado de hombres de confianza a los que recuerda al comienzo del libro X de las Confesiones. Carrión es uno de ellos, y así cuenta el ginebrino la impresión que su visita le produjo:

\footnotetext{
50 París, 23 de enero de 1758. De Masones a Wall. AGS, Estado, Francia, leg. 4535.
}

51 Correspondance complète de Jean-Jacques Rousseau, V, pág. 166. 
Contaba con otro hombre [...]: mi antiguo colega y amigo Carrión, antes secretario titular de la embajada española en Venecia, luego en Suecia, donde estuvo encargado por su corte de muchos negocios, y al fin nombrado realmente secretario de embajada en París. Fue a visitarme en Montmorency cuando menos lo esperaba. Pertenecía a una orden de caballería, cuyo nombre he olvidado, y llevaba una hermosa cruz de pedrería [...] Le hallé siempre el mismo excelente corazón, y cada día más amable ${ }^{52}$.

El relato parece dar a entender que Rousseau no estaba al corriente ni de la presencia de su amigo en París ni de su reciente ingreso en la orden de caballería de Santiago. Por tanto, es muy probable que la correspondencia entre los dos hombres no existiera con anterioridad a aquella visita. Rousseau, de hecho, parece confirmarlo poco después, cuando declara: «Puesto que he vuelto a mis conocidos de Venecia, no debo olvidar uno que con ellos se enlaza, y cuyas relaciones no había interrumpido, así como las otras, sino después de mucho menos tiempo» ${ }^{53}$. El ginebrino se refiere a un tal señor de Jonville, cuya frecuencia de trato no va a tardar mucho en resultarle molesta. El caso de Carrión es distinto: Rousseau rara vez pone el pie en París, a Carrión las ocupaciones no le dan descanso, y la distancia de cuatro leguas que separa la corte de la localidad de Montmorency no es un obstáculo sin importancia. Es difícil en fin que Rousseau y Carrión volvieran a verse después de aquel encuentro de 1758.

La Guerra entre Francia e Inglaterra, declarada oficialmente en mayo de 1756, exige emplearse a fondo: la corona debe quedar informada de los movimientos de los ejércitos, y Carrión trabaja incansablemente con ese objetivo. El trabajo, al menos, tiene su recompensa, y las felicitaciones no tardan en llegar. Durante el mes de octubre de 1758, el embajador de España debe ausentarse para restablecer su salud en las aguas de Pongues, paraje cercano a Fontainbleau. Segundo de abordo, Carrión asume entonces durante tres semanas la obligación de cumplir con los despachos, lo que hace a satisfacción de sus superiores. Ricardo Wall le hace llegar su enhorabuena a través del embajador, quien a su vez no duda en celebrar las aptitudes de su secretario ${ }^{54}$. En fechas próximas, llegan de España noticias que estremecen la vida en la embajada y que exigen de nuevo la práctica del luto. Bárbara de Braganza ha muerto en Aranjuez el 27 de agosto, y la salud de su esposo Fernando VI se deteriora con los días. El «año sin rey»-así conocido más tarde- provoca el pesar entre

\footnotetext{
$52 \quad$ Les Confessions, pág. 508.

53 Les Confessions, pág. 509 (el subrayado es nuestro).

54 París, 6 de noviembre de 1758. De Masones a Wall. AGS, Estado, Francia, leg. 4535.
} 
los miembros de la legación y los españoles residentes en París. Es un largo año de agonía hasta que, finalmente, el 10 de agosto de 1759, el monarca español exhala su último aliento. Cuando la noticia llega a París, se cuelgan de negro las antesalas de la embajada y se impone de nuevo un luto que durará seis meses. En la catedral de Notre-Dame se celebran las exequias por las almas de los difuntos reyes. Asisten el delfín de Francia y sus hermanas las princesas. El embajador de España, para quien se ha reservado una tribuna, acude en compañía de sus iguales y demás ministros extranjeros ${ }^{55}$. Carrión, seguramente, está a su lado. Lamentablemente, su actividad transcurre en la sombra, y las noticias sobre sus quehaceres son sólo esporádicas, insuficientes para comprender el calado de sus servicios. En todo caso, hay buenas razones para suponer que debió emplearse con energía, eficacia e inteligencia, y sacar de más de un aprieto al embajador. Jaime Masones de Lima, en efecto, no brillaba por sus habilidades diplomáticas. El duque de Choiseul, titular de la secretaría de Estado francesa desde diciembre de 1758, celebraba sus modales, su caballerosidad. Masones era el «mejor hombre del mundo», y, a la vez, un inepto, «el más inepto ministro que hubo nunca ${ }^{56}$. Choiseul expresaba su malestar al marqués de Ossun, embajador de Francia en España, quien seguramente trató de convencer a Carlos III de la necesidad de relevar de sus funciones al conde de Montalvo.

El 9 de febrero de 1761, el marqués de Grimaldi llega a París para sustituir a Masones. Sin tiempo que perder, realiza sus visitas de presentación e inicia una intensa ronda de negociaciones. El genovés es hombre capaz, algo que no pasa desapercibido en Versalles, donde muy pronto se gana el favor de la corte y el aprecio de Madame de Pompadour. Grimaldi negocia incansablemente. Por fin, una nueva alianza entre las dos coronas se firma en casa del embajador español el 15 de agosto de 1761. El Tercer Pacto de Familia ya es un hecho. Como consecuencia del mismo, España se compromete a hacer causa común con Francia en contra de los intereses de la corona británica. Uno de los términos del acuerdo reza: «Quien ataca a una corona ataca a la otra», y esa hermandad involucra a España en la guerra contra los ingleses, de la que Francia y España saldrán mal paradas. El 3 de noviembre de 1762 se firman los preliminares de la paz; el 10 de febrero de 1763, en casa del embajador español, el Tratado de París. Estamparon su firma el ministro Choiseul, el duque de Bedford y el marqués de Grimaldi. Con toda seguridad, Carrión presenció el

55 París, 14 de enero de 1760. De Masones a Wall. AGS, Estado, Francia, leg. 4538.

56 Citado en la Tesis doctoral de Paulino García Diego, Jerónimo Grimaldi o el espectador afable, pág. 172. 
acto que ponía fin a las hostilidades y redibujaba el teatro internacional a favor de la todopoderosa Londres.

El zamorano ha estado intachable en el desempeño de sus funciones y, esta vez, las felicitaciones y la recompensa llegan ambas con una inusual inmediatez. Carrión no ha rogado un aumento de sueldo ni recompensa alguna. Es el propio Wall quien ha participado al Rey las buenas prendas e inmejorable actitud del secretario. Carlos III desea premiar su compromiso y decide concederle una gratificación. En su respuesta a Wall, Carrión anota:

Hónrame vd. con una carta de 21 del próximo pasado diciéndome que, con motivo de ver perfeccionada la importante obra de la paz, había vd. hecho presente al Rey lo mucho que yo he trabajado en su negociación al lado de este digno embajador y plenipotenciario, y que este mérito recae sobre otros que no puede contar ninguno de mi clase; y que se ha servido S.M. concederme el sueldo y gajes de su secretario que es una perpetua pensión sobre cualquiera sueldo que goce ${ }^{57}$.

El marqués de Grimaldi se alegra, y, en carta a Ricardo Wall, anota ese mismo día:

He visto por una de las cartas de vd. de 21 de marzo, la merced que el rey ha hecho a D. Francisco de Carrión secretrario de esta embajada del sueldo y gajes de su secretario en atención a sus muchos servicios, y particularmente a los que ha hecho con motivo de la negociación de la paz que se acaba de concluir. Es muy particular la satisfacción que me resulta de la que logra este sujeto; y doy a vd. las gracias por haber hecho presentes al rey sus méritos, pues no dudo le sirva esta recomendación y la protección de vd. para experimentar en adelante la continuación de otras de Su Majestad ${ }^{58}$.

Durante los años parisinos de Carrión, después de ese encuentro de octubre de 1758 , los dos amigos se escriben alguna vez. Venecia los ha unido, y el recuerdo de Italia está presente en sus intercambios. En una carta hoy perdida, Rousseau dirige a su amigo una cariñosa protesta. El Carrión de Venecia no es el Carrión de París. El de ahora es «el magnífico Caballero de Carrión», y el de entonces un secretario de embajada llamado Checco (diminutivo de Francesco). Carrión se indigna y contesta de inmediato el 31 de mayo de 1760. La comparación le parece injuriosa. Y después de declarar su malestar, anota:

\footnotetext{
57 París, 4 de abril de 1763. De Carrión a Wall. AGS, Estado, Francia, leg. 4553.
}

58 París, 4 de abril de 1763. De Grimaldi a Wall. AGS, Estado, Francia, leg. 4553. 
$\mathrm{Al}$ entrar en mi casa hallo, mi muy querido amigo, una carta vuestra firmada la mañana del jueves sin que sepa desde dónde. Me decís que sois mi vecino, y ¿os marcháis sin verme? [...] El muchacho que me ha traído vuestra carta me está esperando y he de arreglarme, de ahí que no pueda detenerme más en escribiros. Sin embargo, permitidme faltaros a vuestras palabras. No puedo considerar de otro modo la comparación injuriosa que hacéis entre Checco y Monsieur de Carrión. $\mathrm{Ni}$ aun en bromas estaría dispuesto a pasárosla. Cualesquiera sean las modificaciones accidentales que mi suerte pueda correr, Carrión y Checco serán siempre el mismo ser para mi querido Jean-Jacques Rousseau. Me parece que si ahora me encontrase ante vos, defendería mi causa a puñetazos y, a pesar de que no tengo un aire colosal, creo que vuestro mejor partido sería vuestra infausta comparación. No necesitaría más que una nueva ocasión de vecindad y un nuevo regreso vuestro sin verme para imaginarme que lo habéis dicho de veras. Estimo vuestra sabiduría, pero un error tal de vuestra parte me parece imperdonable. Adiós, pues no puedo por menos que arrancarme la pluma de las manos. Espero que tengáis a bien corregir esta torpeza. Carrión os ama y abraza de todo corazón, ¿que hace Checco? Addio Caro Caro ${ }^{59}$.

Rousseau ha escrito la carta desde el hôtel de Luxembourg, a sólo un paso del hôtel du Molé donde se aloja Carrión. Un empleado del mariscal ha entregado la carta a su destinatario. Rousseau se disculpa porque abandona París sin haberle visto, y Carrión no puede verle porque la carta va sin señas. La circunstancia disgusta a Carrión, quien renueva sus votos de amistad con el temor de que su amigo haya perdido interés en él.

Es difícil determinar el sentimiento de Rousseau con respecto a Carrión en ese momento, pero es muy probable que su extraña forma de proceder respondiese a un motivo totalmente ajeno a la amistad. Rousseau se había prometido no volver a París, y sólo a regañadientes había aceptado la invitación del mariscal de Luxemburgo. En su decisión había pesado la insistencia del mariscal, pero también el hecho de que, para llegar a su palacete, no era necesario poner «el pie sobre el pavé de París» ${ }^{60}$. En la letra, al menos, seguía sin faltar a su palabra, lo que sí hubiera hecho en el caso de visitar a Carrión. El zamorano, naturalmente, no podía sospechar el motivo, e interpretó el gesto como un acto de desconsideración hacia él. Sin embargo, hay buenas razones para creer que Rousseau apreciaba sinceramente la amistad de Carrión, y que apreciaba también sus dotes intelectuales. En enero de 1761, La Nueva Eloísa está a punto de

59 Correspondance complète de Jean-Jacques Rousseau, VII, págs. 117-118.

60 Les Confessions, pág. 528. 
ponerse en circulación, y Rousseau le pide a su paisano François Coindet (25 de enero) que actúe con diligencia en el envío de los ejemplares «a los primeros de la lista», entre los que incluye a Carrión ${ }^{61}$. Poco después (9 de febrero), el nombre del español vuelve a aparecer en un puesto preferente entre los destinatarios del Prefacio de la Nueva Eloísa ${ }^{62}$. Lo mismo ocurre con la distribución de la Selección de Estampas de la misma obra, el Extracto del Proyecto de Paz Perpetua (4 de marzo) ${ }^{63}$ y el Emilio (16 de mayo de 1762) ${ }^{64}$. Las normas más elementales de cortesía exigían del destinatario una palabra de agradecimiento. Carrión, sin duda, cumplió con la cortesía, pero de las cartas en las que acusaba recibo de las obras, sólo se ha conservado la preparada para el Emilio. Carrión escribe: «No os diré nada sobre vuestro alumno; sólo conozco el avertissement. Aún no he tenido tiempo de abrirlo: sólo Dios sabe cuándo podré leerlo. Pero sé de antemano que me complacerá» ${ }^{65}$. Acto seguido, Carrión muestra su preocupación por Rousseau. Por intermedio de François Coindet, sabe de los quebrantos de salud de su amigo. Desea ir a su encuentro, pero sus ocupaciones se lo impiden: «Si pudiera disponer de un par de días en esta estación, los aprovecharía, y os aseguro que cumpliría con el propósito de veros y abrazaros». Y más adelante anota: «Soy ahora casi extranjero en París, no teniendo por así decir otro descanso que el espectáculo de los italianos, del que disfruto sólo de cuando en cuando» ${ }^{66}$. Otra vez, en fin, el recuerdo de Italia.

El 7 de junio, la Facultad de Teología de la Sorbona condena el Emilio por atentar contra la fe y la moral. Dos días después, el Parlamento de París decide quemar la obra en sus escalinatas y dictar orden de arresto contra su autor. Avisado por un empleado del mariscal de Luxemburgo, Rousseau abandona Francia a toda prisa camino de Suiza, su país de origen. Por su parte, Carrión sigue todavía un año más en París. El 7 de mayo de 1763, se encuentra en Marly, residencia real, con el mariscal de Luxemburgo. Los dos hablan de Rousseau. El mariscal escribe al ginebrino ese mismo día. Carrión y él han departido de «muchas cosas», y el español tiene previsto enviarle una carta por intermedio suyo. Nada se ha sabido de esa carta. Quizás no la escribió o, si lo hizo, es probable que el zamorano lo hiciera al poco tiempo, ignorante aún de su nueva comisión. Así se desprende de una carta de 1767, transcurridos casi cuatro años, en la que el ginebrino, en respuesta a los ataques de Voltaire, defiende su

\footnotetext{
${ }_{61}$ Correspondance complète de Jean-Jacques Rousseau, VIII, pág. 27.

62 Correspondance complète de Jean-Jacques Rousseau, págs. 67-68.

63 Correspondance complète de Jean-Jacques Rousseau, pág. 214.

64 Correspondance complète de Jean-Jacques Rousseau, X, pág. 247

65 Correspondance complète de Jean-Jacques Rousseau, XI, págs. 6-7.

${ }_{66}$ Correspondance complète de Jean-Jacques Rousseau, XI, págs. 6-7.
} 
«bilan veneciano», y recurre para su defensa al «Caballero de Carrión, entonces mi colega y mi amigo», y a quien imagina todavía en París. El ginebrino se equivoca. El 30 de mayo de 1763, poco después de firmado el Tratado de Paz, poco después también de aquel encuentro en Marly, se ha propuesto a Carrión para ocupar la secretaría de la embajada de España en Londres ${ }^{67}$, adonde ha pasado sin tiempo que perder: urge repatriar a los prisioneros españoles que Inglaterra retiene en sus costas, y el zamorano debe averiguar su paradero, encargarse de su manutención y fletar navíos para devolverlos a España ${ }^{68}$. Además, el Príncipe de Maserano, nuevo embajador de España en Gran Bretaña, no ha llegado aún a su destino, circunstancia que hace más necesaria la intervención de Carrión.

\section{Londres}

El 22 de junio, después de despedirse de la Familia Real en Versalles, Carrión inicia su viaje a Londres, adonde llega al cabo de unos pocos días. Pronto inicia sus gestiones. Para octubre, ya puede anunciar que son 813 los prisioneros retenidos por los ingleses y que Pedro de Errecarte, comerciante español en Londres, corre con los gastos de repatriación. Por esas fechas, cinco oficiales prisioneros de Manila, víctimas de la ferocidad de los ingleses, solicitan el amparo de las autoridades españolas. Carrión parte con ellos el puchero mientras espera la llegada del embajador, lo que tiene lugar poco después, el 26 de noviembre. Al poco de llegar, el príncipe de Maserano come en casa del embajador de Francia. Carrión debe acompañarle, pero está enfermo. «Su salud — escribe el nuevo embajador- está muy quebrantada ${ }^{69}$.

\section{Madrid}

La pista del zamorano se pierde luego durante algunos meses, hasta el verano de 1764. Por decreto de 17 de agosto, el rey Carlos III ha decidido nombrarlo contador de las órdenes militares. Es un empleo con el que la corona reconoce la calidad de sus servicios, y del que Carrión va a tomar posesión el 22 de diciembre para mantenerse en él hasta el final de su vida. Poco se sabe de su vida durante este último período. El 13 de marzo de 1765, contrae matri-

\footnotetext{
67 Aranjuez, 30 de mayo de 1763. De Wall a Grimaldi. AGS, Estado, Francia, leg. 6554.

68 Aranjuez, 30 de mayo de 1763. De Wall a Grimaldi. AGS, Estado, Francia, leg. 4554.

69 Londres, 29 de noviembre de 1763. De Maserano a Grimaldi. AGS, Estado, Inglaterra, leg. 6956.
} 
monio en la parroquia madrileña de S. Sebastián con doña Antonia Soto Posada y Herrera, natural de la villa de Madrid y veinticinco años más joven que él ${ }^{70}$. Todavía en 1765, es nombrado Académico de Honor de la Real Academia de Bellas Artes de San Fernando en junta ordinaria celebrada el 5 de mayo ${ }^{71}$. El nombramiento venía precedido de un brevísimo memorial redactado por Carrión en el que este dejaba clara su relación con las actividades promovidas por la academia madrileña durante aquellos años. Sin concurrir en él «las circunstancias de experiencia práctica de las artes», Carrión aseguraba no haber dejado de «aplicarse al conocimiento teórico de ellas con la comparación de sus objetos en los diferentes países que ha conocido, de Italia, Alemania, Francia e Inglaterra y residencias largas que le han proporcionado sus anteriores destinos en las cortes de Venecia, Estocolmo, Viena, París y Londres» ${ }^{72}$. No hay motivos para desconfiar de su confesión. Carrión era un hombre culto. De ello da buena muestra su correspondencia con Rousseau, pero también, por ejemplo, una carta de Grimaldi a Manuel de Roda de 1762, año en que aquél ejercía aún de embajador en París mientras este lo hacía de agente de preces en Roma. El futuro Ministro de Gracia y Justicia deseaba adquirir libros y recibir puntual información del proceso entablado en Francia contra la Compañía de Jesús. Grimaldi accedía a su petición y, para ello, le ponía en contacto con su estimado secretario ${ }^{73}$.

El 30 de enero de 1770, Carrión es elegido diputado del común por Ma$\operatorname{drid}^{74}$. Cinco años después, en 1775, su nombre integra la primera lista de miembros de la Real Sociedad Económica Matritense, institución animada por la filantropía propia del setecientos europeo y a cuyas asambleas semanales Carrión debió de asistir a partir de entonces ${ }^{75}$. El 24 de agosto de 1776, fallece su esposa. La pérdida deja a Carrión viudo y sin descendencia. En fechas próximas, quizás como consecuencia de la defunción de su mujer, el zamorano abandona el inmueble que había ocupado en la céntrica calle de la Magdalena para ocupar otro en la vecina Carrera de San Francisco, donde lo sitúa la Guía

70 Archivo Provincial de San Esteban de Madrid, libro de matrimonios, no 25, f. 159.

71 Actas de sesiones de la Real Academia de Bellas Artes de San Fernando. Libros de actas de las sesiones particulares, ordinarias, generales, extraordinarias, públicas y solemnes (1752-1784). Actas del año 1765, págs. 302r y 302v. En http://www.cervantesvirtual.com/obra-visor-din/actas-del-ano-1765--0/html/

72 Archivo de la Real Academia de Bellas Artes de San Fernando, exp. 6-93-5.

73 París, de Grimaldi a Roda. 30 de marzo y 11 de mayo de 1762. Biblioteca Nacional, mss. 71711 y 8.

74 De lo que informa el Journal politique ou Gazette des gazettes en estos términos : «Le 30 du mois dernier, le Corrégidor \& les Electeurs des paroisses de cette ville s'étant assemblés pour élire des députés \& le représentant du peuple, qui doivent être de service de cette année avec don Antoine de la Vega \& don Manuel Gonzalo del Río, ils élurent pour députés don François de la Torre \& Don François-Xavier de Carrión, \& pour représentant Don Alexandre Ballejo» [Bouillon, feb. 1770, $1^{\text {a }}$ quincena, pág. 38].

75 Archivo de la Real Sociedad Económica Matritense, leg. 1, exp. 4. 
de forasteros de $1778^{76}$. La última noticia es de 1779 , año en que aparece en la lista de suscriptores de la obra Crónicas de los Reyes de Castilla. El 12 de febrero, enfermo, escribe sus últimas voluntades. Tres días después, el 15 de febrero de 1779, tiene lugar su defunción. Amortajado con el manto capitular de la orden de Santiago, recibió sepultura en la Iglesia Parroquial de San Andrés de Madrid, junto a los restos de su esposa.

La Gaceta de Madrid publicó su necrológica el 26 de febrero de 1779. El 2 de julio se efectuó la tasación de sus bienes para su venta en pública almoneda. El inventario, de 29 hojas, permite pensar que Carrión llevó al final una vida acomodada. Disponía de criados, coche grande y berlina, y de un ajuar bien provisto del que no estaban ausentes el oro, la plata, y otros materiales preciosos. Entre tantos bienes, algunas partituras de música (quizás italiana), varias monedas extranjeras y la cruz de pedrería que Rousseau vio rodeando su cuello. Gracias al apunte del tasador, sabemos que la cruz estaba guarnecida de rubíes, rematada por un topacio, y alojada en una venera en forma de concha. En cuanto a su biblioteca, el maestro librero la tasó en 18000 reales y fue vendida en pública almoneda. Por desgracia, el inventario de sus bienes no incluye la relación de obras que integraban su biblioteca, aunque parece poco probable que las obras de Rousseau, autor prohibido, hubieran llegado a España de su mano. Su retrato y el de su esposa, consignados también en el inventario, se han perdido ${ }^{77}$.

\section{Consideración final}

Francisco Xavier de Carrión y Ribas es hoy un desconocido, pero los documentos conservados en varios archivos españoles nos hablan de un hombre de un mérito excepcional. Su capacidad de trabajo es indiscutible, su sentido del deber también. Al servicio de tres Borbones, Felipe V, Fernando VI y Carlos III, fue secretario de embajada en media Europa. Venecia, Estocolmo, Viena, París, Londres y finalmente Madrid dibujaron el itinerario de su vida. Si en sus primeros años de carrera apenas le alcanzaba el sueldo para vivir con decencia, logró por méritos vivir holgadamente. Caballero de la Orden de Santiago primero, miembro de la Real Academia de San Fernando y de la Sociedad Matritense después, fue un hombre culto que dominó varias lenguas. Salió de España

76 Kalendario Manual y Guía de Forasteros en Madrid para el año de M. DCC. LXXVIII, Madrid, Real Imprenta de la Gaceta, pág, 59. Es el Kalendario de 1773, pág. 57 el que, cinco años antes, sitúa a Carrión en la calle de la Magdalena.

77 El inventario de bienes se conserva en AMB, Fondo Casa de Doña Soledad González, leg. 2, exp. 29. 
sabiendo sólo español, y después de «correr cortes» adquirió el dominio de las lenguas italiana, alemana, sueca, francesa e inglesa. Se relacionó con lo más granado de España. Mostró sensibilidad por las letras, y conoció a Rousseau, con quien compartió amores y andanzas de juventud durante los días de ambos en la ciudad de Venecia. De la correspondencia entre ambos y de la semblanza que el ginebrino dejó de él se desprende que fue un hombre dotado de excelente corazón, generoso y honesto. Todavía en 1774, muy lejano ya el encuentro de Montmorency, los dos amigos se escriben. Rousseau responde a una carta de Carrión del año anterior, y este responde de nuevo por intermedio del duque de Alba, amigo del ginebrino ${ }^{78}$. Ninguna de estas cartas se ha conservado y sólo sabemos de su existencia por testimonios indirectos. Dice Rousseau en las Confesiones que nunca saldó con el zamorano una deuda de cincuenta escudos ${ }^{79}$. Sin embargo, que el nombre de Francisco Xavier de Carrión y Ribas no haya caído en el olvido sólo es mérito de Rousseau. A la postre, su deuda quedó bien saldada.

78 No se conoce el origen de las relaciones de Fernando da Silva Álvarez de Toledo, XII duque de Alba, con Rousseau y Carrión. Carrión le escribe al duque desde Estocolmo el 3 de mayo de 1754. El duque ocupaba entonces interinamente la secretaría de Estado, que pasaría a manos de Ricardo Wall tras la defunción el 8 de abril de José de Carvajal, su anterior titular. Es posible que Carrión conociera personalmente al duque al menos desde 1765, año en que Carrión es nombrado académico de honor de la Real Academia de San Fernando, de la que el duque era «consiliario» desde 1753.

79 Les Confessions, pág. 313. 